Contribution from the department of Coordination Chemistry

State University, P.O. Box 75 Leyden, The Netherlands

\title{
Spectroscopic and Magnetic Properties of Compounds Containing the Hydrazinium Cation as a Ligand
}

\section{A. Nieuwpoort* and J. Reedijk}

Received July 28, 1972

The compounds of formula $\mathrm{M}\left(\mathrm{N}_{2} \mathrm{H}_{5}\right)_{2}\left(\mathrm{SO}_{4}\right)_{2}$, with $\mathrm{M}$ $=\mathrm{Mn}, \mathrm{Fe}, \mathrm{Co}, \mathrm{Ni}, \mathrm{Cu}, \mathrm{Zn}$ and $\mathrm{Cd}^{\prime \prime}$, have been investigated by means of infrared spectroscopy, ligand-field spectroscopy, magnetic susceptibility measurements, electron paramagnetic resonance spectra, and Mössbauer measurements.

The spectroscopic investigations indicate a distorted octahedral coordination for the metal ions. The results are in agreement with a previous crystal structure determination of $\mathrm{Zn}\left(\mathrm{N}_{2} \mathrm{H}_{5}\right)_{2}\left(\mathrm{SO}_{4}\right)_{2}$. Most of the spectra can be interpreted simply on the basis of tetragonal compressed octahedral geometry. The ligand $\mathrm{N}_{2} \mathrm{H}_{5}^{+}$seems to behave as a normal nitrogendonor ligand, as reflected by its spectroscopic parameters.

Evidence for rhombic distortions came from EPR spectra of the copper and manganese compounds.

\section{Introduction}

Coordination compounds containing positively charged ligands occur rather seldom and are subject of growing interest. ${ }^{1-5}$ Examples of such positively charged ligands are $\left(\mathrm{CH}_{3}\right)_{3} \mathrm{~N}^{+}-\mathrm{NH}_{2}{ }^{4},\left(\mathrm{CH}_{3}\right)_{3} \mathrm{~N}^{+}-\left(\mathrm{CH}_{2}\right)_{2-}$ $\mathrm{NH}_{2}{ }^{2}$ and $\mathrm{H}_{3} \mathrm{C}-\mathrm{N}_{(}^{-\left(\mathrm{CH}_{2}\right)_{2}}, \mathrm{~N}^{+}\left(\mathrm{CH}_{3}\right)_{2}{ }^{5}$

Some of these potential ligands are known to occur also as uncoordinated cations in coordination compounds ${ }^{46}$ of the type $\mathrm{L}^{+}\left(\mathrm{MX}_{\mathrm{n}}{ }^{-}\right)$such as in $\mathrm{L}_{2} \mathrm{~L}_{2}{ }^{+}\left(\mathrm{NiCl}_{4}\right)^{2-}$

An older group of compounds is the series of metal hydrazinium sulfates of formula $\mathrm{M}\left(\mathrm{N}_{2} \mathrm{H}_{5}\right)_{2}\left(\mathrm{SO}_{4}\right)_{2}$, that is known, from structural studies, to contain metal ions coordinated distorted octahedrally by two $\mathrm{N}_{2} \mathrm{H}_{5}{ }^{+}$ ions (trans) and two bidentate bridging sulfate anions. ${ }^{1,7}$

Spectroscopic and magnetic studies on these com-

- Present address: Department of Inorganlc Chemistry The Uni-

versity, Nijmegen. ersity, Julianalaan 136, Delft, The Netherlands.

1) C.K. Prout and H.M. Powell, I. Chem. Soc., 41771961

(2) J.V. Quagliano, I.T. Summers, S. Kida, and L.M. Vallarino,

(3) V.L. Goedken. I.V. Quagllano, and L.M. Vallarlno, ibid., 8,

(4) V.L. Goedken. L.M. Vallarino, and I.V. Quagliano, ibid, , 10,

(5) A.S.N. Murthy, J.V. Quagllano, and L.M. Vallarino, Inorg.

(6) A. Braibanti and A. Tiripacchio, Gazz. Chim. Ital., 96, 1580 (66).

(7) D.W. Hand C.K. Prout, J. Chem. Soc., (A), 168 (1966) pounds have not been mentioned in the literature. The purpose of the present study is to fill up this omission and to investigate possible relationships between spectroscopic parameters and structural information for these unsually distorted octahedral compounds. In addition we were interested in the ligandfield spectral parameters of $\mathrm{N}_{2} \mathrm{H}_{5}{ }^{+}$compared with $\mathrm{N}_{2} \mathrm{H}_{4}$.

Therefore ligand-field spectra, infrared spectra, EPR spectra Mössbauer spectra and magnetic susceptibility measurements were performed on a number of suitable compounds $\mathrm{M}\left(\mathrm{N}_{2} \mathrm{H}_{5}\right)_{2}\left(\mathrm{SO}_{4}\right)_{2}$.

\section{Experimental Section}

Starting materials. Bishydrazinium sulfate (Aldrich) was used without purification. Metal(II) sulfates were commercially available as the hydrates.

Preparation of the compounds. A solution of the metal sulfates $(0.01 \mathrm{moles})$ in $25 \mathrm{ml}$ of hot water was added to a hot solution of $\mathrm{N}_{2} \mathrm{H}_{6} \mathrm{SO}_{4}(0.02$ moles $)$ in $15 \mathrm{ml}$ of water. In most cases the compounds $\mathrm{M}$ $\left(\mathrm{SO}_{4}\right)_{2}\left(\mathrm{~N}_{2} \mathrm{H}_{5}\right)_{2}$ immediately separated as powders, except for $\mathrm{M}=\mathrm{Mn}^{\mathrm{II}}$ wehere cooling to about $10^{\circ} \mathrm{C}$ was necessary to obtain the solid compound. The crystals were collected on a glass filter, washed subsequently with water, ethanol and diethylether, and finally dried in vacuo $\left(0.1 \mathrm{~mm} / \mathrm{Hg}\right.$ at about $40^{\circ}-50^{\circ}$ C). The manganese and copper-doped $\mathrm{Zn}$ - and $\mathrm{Cd}$ compounds were prepared similarly, but with the addition of small amounts (about $1 \%$ ) of $\mathrm{MnSO}_{4}$ and $\mathrm{CuSO}_{4}$ respectively.

Analyses. The compounds were checked for purity by metal(II) analyses and for a few cases by nitrogen and hydrogen analyses (carried out at organisch chemisch instituut, TNO, P.O. Box 5009, Utrecht).

Measurements. Infrared spectra were recorded on a Unicam SP-1200 spectrophotometer $\left(4000-400 \mathrm{~cm}^{-1}\right)$ and on Hitachi EPI-L (700-200 $\left.\mathrm{cm}^{-1}\right)$, as Nujol mulls between sodium chloride or polythene plates, and also as pressed $\mathrm{KBr}$ or CsI discs.

Ligand-field spectra of the solid compounds were obtained by the diffuse reflectance method on a Beckman DK-2A instrument as described elsewhere. ${ }^{8}$

(8) J. Reedljk, Rec. Trav, Chim. 89, 993 (1970). 
Table I. Coordination compounds containing the ligand $\mathrm{N}_{2} \mathrm{H}_{5}{ }^{+}$.

\begin{tabular}{|c|c|c|c|c|}
\hline Compound & Colour & X-ray type & calculated & found \\
\hline $\begin{array}{l}\mathrm{Mn}\left(\mathrm{N}_{2} \mathrm{H}_{5}\right)_{2}\left(\mathrm{SO}_{4}\right)_{2} \\
\mathrm{Fe}\left(\mathrm{N}_{2} \mathrm{H}_{5}\right)_{2}\left(\mathrm{SO}_{4}\right)_{2} \\
\mathrm{Co}\left(\mathrm{N}_{2} \mathrm{H}_{5}\right)_{2}\left(\mathrm{SO}_{4}\right)_{2} \\
\mathrm{Ni}\left(\mathrm{N}_{2} \mathrm{H}_{5}\right)_{2}\left(\mathrm{SO}_{4}\right)_{2} \\
\mathrm{Cu}\left(\mathrm{N}_{2} \mathrm{H}_{5}\right)_{2}\left(\mathrm{SO}_{4}\right)_{2} \\
\mathrm{Zn}\left(\mathrm{N}_{2} \mathrm{H}_{5}\right)_{2}\left(\mathrm{SO}_{4}\right)_{2} \\
\mathrm{Cd}\left(\mathrm{N}_{2} \mathrm{H}_{5}\right)_{2}\left(\mathrm{SO}_{4}\right)_{2}\end{array}$ & $\begin{array}{l}\text { white } \\
\text { pale green } \\
\text { rose } \\
\text { green } \\
\text { blue } \\
\text { white } \\
\text { white }\end{array}$ & $\begin{array}{l}\mathbf{A} \\
\mathbf{A} \\
\mathbf{A} \\
\mathbf{A} \\
\mathbf{A}^{\prime} \\
\mathbf{A} \\
\mathbf{A}^{\prime \prime}\end{array}$ & $\begin{array}{l}17.5 \\
18.0 \\
18.6 \\
18.5 \\
19.7 \\
20.2 \\
30.3\end{array}$ & $\begin{array}{l}18.3^{a} \\
18.2^{b} \\
18.0^{c} \\
17.4^{c} \\
19.6^{d} \\
20.1^{b} \\
30.3^{2}\end{array}$ \\
\hline
\end{tabular}

Table II. Infrared spectra of $\mathrm{M}\left(\mathrm{N}_{2} \mathrm{H}_{5}\right)_{2}\left(\mathrm{SO}_{4}\right)_{2}, \quad\left(\mathrm{~N}_{2} \mathrm{H}_{5}\right)_{2} \mathrm{SO}_{4}$ and $\mathrm{N}_{2} \mathrm{H}_{4}$.

\begin{tabular}{|c|c|c|c|}
\hline Assignments & $\begin{array}{l}\mathrm{Mn}\left(\mathrm{N}_{2} \mathrm{H}_{3}\right)_{2}\left(\mathrm{SO}_{4}\right)_{2} \\
\text { solid state }\end{array}$ & $\begin{array}{l}\left(\mathrm{N}_{2} \mathrm{H}_{5}\right)_{2} \mathrm{SO}_{4} \\
\text { solid } \\
\end{array}$ & $\begin{array}{l}\mathrm{N}_{2} \mathrm{H}_{4}{ }^{10} \\
\text { liquid }\end{array}$ \\
\hline & $\left\{\begin{array}{l}3290 \\
3230\end{array}\right.$ & $\begin{array}{l}3240 \\
3135\end{array}$ & 3332 \\
\hline \multirow{3}{*}{ N-H stretchings } & 3160 & & 3189 \\
\hline & 3070 & 3030 & \\
\hline & 3000 & 2975 & \\
\hline $\begin{array}{l}\text { Strongly H-bridged } \\
\mathrm{N}-\mathrm{H} \text { stretchings }\end{array}$ & 2940 & & \\
\hline \multirow[t]{3}{*}{$\mathrm{N}-\mathrm{H}$ stretchings } & 2760 & & \\
\hline & $\begin{array}{l}2700 \\
2660\end{array}$ & $\begin{array}{l}2690 \\
2580\end{array}$ & \\
\hline & 1630 & 1625 & 1608 \\
\hline \multirow[t]{4}{*}{$\mathrm{N}-\mathrm{H}$ bendings } & 1605 & 1600 & \\
\hline & 1575 & 1575 & \\
\hline & 1500 & $\begin{array}{l}1515 \text { sh } \\
1495\end{array}$ & \\
\hline & & 1410 & \\
\hline \multirow{2}{*}{$\mathrm{N}-\mathrm{H}$ bending } & 1310 & & 1324 \\
\hline & & 1240 & 1283 \\
\hline \multirow{2}{*}{$\begin{array}{l}\text { N-H wagging } \\
\text { S-O asymm. stretch }\end{array}$} & $1175 \mathrm{sh}$ & 1185 & 1098 \\
\hline & 1075 & $\begin{array}{l}1110 \\
1085\end{array}$ & 1042 \\
\hline N-H rocking & & 970 & \\
\hline N-N stretching & 1005 & 965 & 871 \\
\hline S-O symm. stretch & 990 & 988 & \\
\hline Other bands & $a$ & & \\
\hline
\end{tabular}

a Bands below $700 \mathrm{~cm}^{-1}$ are listed in Table III.

Table ill. Far-infrared spectra $\left(700-200 \mathrm{~cm}^{-1}\right)$ of $\mathrm{M}\left(\mathrm{N}_{2} \mathrm{H}_{5}\right)_{2}\left(\mathrm{SO}_{1}\right)_{2}$.

\begin{tabular}{|c|c|c|c|c|c|c|c|c|c|c|}
\hline \multirow{2}{*}{$\frac{\text { Compound }}{\mathrm{Cd}\left(\mathrm{N}_{2} \mathrm{H}_{3}\right)_{2}\left(\mathrm{SO}_{4}\right)_{2}}$} & \multicolumn{4}{|c|}{$v_{f}\left(\mathrm{SO}_{4}{ }^{2-}\right)+\mathrm{N}-\mathrm{H}$ def. } & \multicolumn{2}{|c|}{$\begin{array}{c}\mathrm{N}-\mathrm{N} \text { bending } \\
+v_{2}\left(\mathrm{SO}_{4}^{2-}\right)\end{array}$} & \multicolumn{4}{|c|}{$\begin{array}{l}\text { Other bands } \\
M-N \text { and } M-O\end{array}$} \\
\hline & 638 & 616 & 607 & 572 & 478 & $456 \mathrm{~m}$ & 360 & 280 & & 220 \\
\hline $\operatorname{Mn}\left(\mathrm{N}_{2} \mathrm{H}_{5}\right)_{2}\left(\mathrm{SO}_{6}\right)_{2}$ & 638 & 621 & 604 & 558 & 479 & $460 \mathrm{w}$ & 360 & 285 & & 225 \\
\hline $\mathrm{Fe}\left(\mathrm{N}_{2} \mathrm{H}_{5}\right)_{2}\left(\mathrm{SO}_{4}\right)_{2}$ & 639 & 621 & 599 & 560 & 482 & $462 \mathrm{vw}$ & 578 & 300 & & \\
\hline $\mathrm{Zn}\left(\mathrm{N}_{2} \mathrm{H}_{3}\right)_{2}\left(\mathrm{SO}_{4}\right)_{\gamma}$ & 647 & 622 & 606 & 589 & 488 & $464 \mathrm{vw}$ & 395 & 300 & & 235 \\
\hline $\mathrm{Ni}\left(\mathrm{N}_{2} \mathrm{H}_{5}\right)_{2}\left(\mathrm{SO} \mathrm{O}_{4}\right)_{2}$ & 646 & 620 sh & 609 & 593 & 485 & & 404 & 305 & & 235 \\
\hline $\mathrm{Cu}\left(\mathrm{N}_{2} \mathrm{H}_{3}\right)_{2}\left(\mathrm{SO}_{4}\right)_{2}$ & 655 & & 614 & 600 & 492 & & 420 & 315 & & 240 \\
\hline $\mathrm{Co}\left(\mathrm{N}_{2} \mathrm{H}_{3}\right)_{2}\left(\mathrm{SO}_{4}\right)_{2}$ & 679 & 640 & 610 & & 488 & & 446 & 335 & 280sh & 235 \\
\hline
\end{tabular}

X-ray powder diagrams were performed on a Guinier camera, using $\mathrm{Cu}-\mathrm{K} \alpha$ radiation. Mössbauer spectra were obtained at temperatures between 80 and $300^{\circ}$ $\mathrm{K}$ on commercial ELRON instruments, furnished with a ${ }^{57} \mathrm{Co}$ source diffused into $10 \mathrm{um} \mathrm{Pd}$ foil. Sodium nitroprusside was used as a standard.

Magnetic susceptibilities were performed on a Faraday balance in the $80-300 \mathrm{~K}$ region, using CoHg$(\mathrm{SCN})_{4}$ as a calibrating standard tables. Diamagnetic corrections were taken from standard. EPR spectra of the powdered compounds were obtained at $\mathrm{X}$ - and
Q-band frequencies on Varian instruments as described elsewhere.'

\section{Results}

The compounds under investigation are listed in Table I, with analytical results, colours and X-ray

(9) R.D. Dowsing, B. Nieuwenhuyse, and J. Reedijk, Inorg. Chim. Acta, 5, 301 (1971). (10) J.R. During, S.F. Busch, and E.E. Mercer, J. Chem. Phys.,
4238 (1966). 
Table IV. Ligand-field spectra and calculated parameters $(\mathrm{kK})$ of compounds $\mathrm{M}\left(\mathrm{N}_{2} \mathrm{H}_{3}\right)_{2}\left(\mathrm{SO}_{4}\right)_{2}$.

\begin{tabular}{|c|c|c|c|c|c|c|}
\hline \multirow[b]{2}{*}{ Compounds } & \multirow[b]{2}{*}{$\mathbf{T}\left({ }^{\circ} \mathbf{K}\right)$} & \multirow[b]{2}{*}{ Bandmaxima } & \multicolumn{4}{|c|}{ Parameters } \\
\hline & & & $\mathrm{Dq}$ & -Ds & $-D t$ & B \\
\hline $\mathrm{Fe}\left(\mathrm{N}_{2} \mathrm{H}_{5}\right)_{2}\left(\mathrm{SO}_{4}\right)_{2}$ & $\begin{array}{l}300 \\
100\end{array}$ & $\begin{array}{ll}11.2 & 9.1 \\
11.8 & 9.3\end{array}$ & 0.91 & $0.4^{a}$ & $0.1^{a}$ & - \\
\hline $\mathrm{Co}\left(\mathrm{N}_{2} \mathrm{H}_{3}\right)_{2}\left(\mathrm{SO}_{4}\right)_{2}$ & 300 & $21.0 \mathrm{sh} \quad 19.9 \quad 18.0 \mathrm{sh} \quad 9.9 \quad 8.5$ & $\begin{array}{l}0.93 \\
0.92\end{array}$ & & $\begin{array}{l}0.1 \\
0.12 b\end{array}$ & $0 \overline{80}$ \\
\hline & 100 & $\begin{array}{lllll}21.2 \mathrm{sh} & 20.1 & 18.0 \mathrm{sh} & 10.1 & 8.7\end{array}$ & 0.94 & 0.5 & 0.11 & \\
\hline $\mathrm{Ni}\left(\mathrm{N}_{2} \mathrm{H}_{5}\right)_{2}\left(\mathrm{SO}_{4}\right)_{2}$ & 300 & $26.6 \quad 15.6 \quad 13.5 \mathrm{sh} \quad 9.4$ & 0.93 & $0.4 c$ & $0.1^{c}$ & 0.87 \\
\hline $\mathrm{Cu}\left(\mathrm{N}_{2} \mathrm{H}_{5}\right)_{2}\left(\mathrm{SO}_{4}\right)_{2}$ & $\begin{array}{l}100 \\
300\end{array}$ & $\begin{array}{ll}26.9 & 15.9 \\
14.0 & 10.0 \mathrm{sh}\end{array}$ & 0.95 & 0.5 & 0.1 & 0.87 \\
\hline $\mathrm{Cu}^{2+}$ in $\mathrm{Zn}\left(\mathrm{N}_{2} \mathrm{H}_{5}\right)_{2}\left(\mathrm{SO}_{4}\right)_{2}$ & 300 & 13.3 & & & & \\
\hline
\end{tabular}

${ }^{a} \mathrm{Ds}$ and Dt obtained in combination with Mössbauer and Magnetic data; the errors are $10 \%$ for Ds and $20 \%$ for Dt; ${ }^{b} \mathrm{Ob}$ tained from visible spectra only; the errors are $10 \%$ for Ds and $10 \%$ for Dt. ${ }^{c}$ Obtained from the visible spectra; the values for Ds and Dt are upper limits obtained from band widths and a calculation with spin-orbit interaction (assuming $\lambda=-300$ $\left.\mathrm{cm}^{-1}\right)$.

Table V. Mössbauer spectra and magnetic measurements of $\mathrm{Fe}\left(\mathrm{N}_{2} \mathrm{H}_{3}\right)_{2}\left(\mathrm{SO}_{4}\right)_{2}$.

\begin{tabular}{|c|c|c|c|c|c|}
\hline \multirow{2}{*}{$\begin{array}{l}\text { Temperature } \\
\left({ }^{\circ} \mathrm{K}\right)\end{array}$} & \multicolumn{2}{|c|}{ Mössbauer data } & \multicolumn{2}{|c|}{ Magnetic data } & \multirow{2}{*}{$\begin{array}{l}\text { After a } \theta=-8 \\
\text { correction }\end{array}$} \\
\hline & C.S.a & Q.S. ${ }^{a}$ & $X\left(10^{6} \mathrm{cgs}\right)^{b}$ & $\mu($ B.M.) $c$ & \\
\hline${ }_{0}^{340}{ }_{d}^{d}$ & 1.42 & 2.99 & & 5.24 & \\
\hline $\begin{array}{l}250 \\
254\end{array}$ & $\begin{array}{l}1.46 \\
1.48\end{array}$ & $\begin{array}{l}3.16 \\
3.29\end{array}$ & 11690 & 5.20 & 5.28 \\
\hline 242 & & & 13910 & 5.22 & 5.28 \\
\hline 220 & 1.50 & 3.41 & 15270 & 5.18 & 5.28 \\
\hline 198 & 1.52 & 3.49 & 16850 & 5.16 & $5.27^{3}$ \\
\hline 175 & & & 18820 & 5.15 & 5.27 \\
\hline 146 & 1.55 & 3.60 & 22280 & 5.12 & 5.25 \\
\hline 135 & & & 23900 & 5.10 & 5.23 \\
\hline 117 & 1.57 & 3.68 & 27090 & 5.06 & 5.21 \\
\hline 105 & 1.57 & 3.70 & 29920 & 5.02 & 5.19 \\
\hline 78 & 1.59 & 3.76 & 37400 & 4.86 & 5.11 \\
\hline
\end{tabular}

${ }^{a}$ Mössbauer parameters are in $\mathrm{mm} / \mathrm{s}$, relative to sodium nit roprusside; C.S. values are accurate to \pm 0.01 ; Q.S. values. are accurate to $\pm 0.02 \mathrm{~mm} / \mathrm{s}$; Mössbauer temperatures arc accurate to $\pm 3^{3}$. b Susceptibilities are corrected for diamagnetism by $300 \times 10^{-6} \mathrm{cgs}$ units. ${ }^{c}$ Magnetic moments are accurate to \pm 0.05 B.M.; relative errors are \pm 0.01 B.M. since the measurements are from the same sample. $d$ The value reported in ref. 1.

Table VI. EPR spectra of $\mathrm{Cu}^{2+}$ and $\mathrm{Mn}^{2+}$ in $\mathrm{M}\left(\mathrm{N}_{2} \mathrm{H}_{5}\right)_{2}\left(\mathrm{SO}_{4}\right)_{2}$.

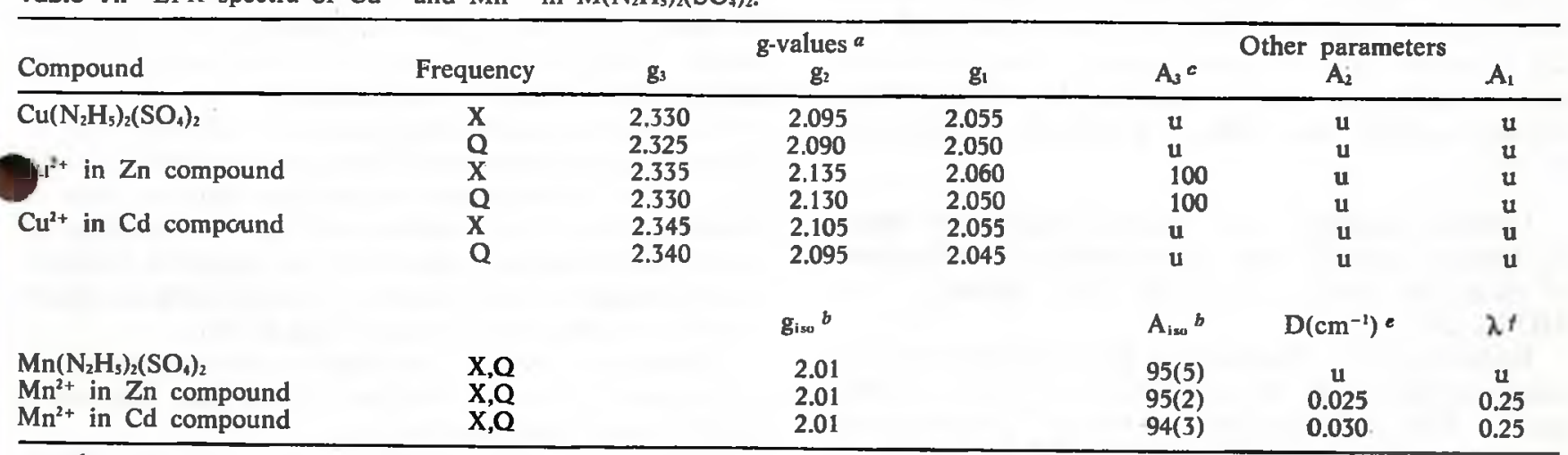

${ }^{a} \mathrm{~g}$-values are accurate to $\pm 0.005 ;{ }^{b}$ the g-value is $\pm 0.01 ; c$ The value for $\mathrm{A}_{3}$ is \pm 5 Gauss; $d$ The uncertainty is indicated between parentheses; $e$ The $D$-values are $\pm 0.005 \mathrm{~cm}^{-1} ; \quad i$ is defined as $E / D$ and is accurate to \pm 0.05 ; $u$ is unresolved.

types. The division into the $\mathrm{X}$-ray types was made according to the line patterns, that are very similar in $d$-values and relative intensities. Only the $\mathrm{Cu}^{\text {II }}$ and $\mathrm{Cu}^{\mathrm{II}}$ compounds show slightly different line patterns. The infrared spectra of all compounds are very similar in the high-frequency region. For one compound the observed infrared bands are listed and compared with $\mathrm{N}_{2} \mathrm{H}_{4}$ and with $\left(\mathrm{N}_{2} \mathrm{H}_{5}\right)_{2} \mathrm{SO}_{4}$ in Table II. Table III gives the far-IR spectra of the com- pounds $\left(700-200 \mathrm{~cm}^{-1}\right)$ together with some tentative assignments.

In Table IV the ligand-field maxima of the coloured compounds are presented along with some calculated parameters.

Magnetic susceptibility and Mössbauer results of $\mathrm{Fe}\left(\mathrm{N}_{2} \mathrm{H}_{5}\right)_{2}\left(\mathrm{SO}_{4}\right)_{2}$ are listed in Table $\mathrm{V}$, whereas the EPR data of the $\mathrm{Mn}$ and $\mathrm{Cu}$ compounds are given in Table VI. 


\section{Discussion}

Structure of the compounds. A two-dimensional X-ray analysis by Prout and Powell in 1961 has shown that $\mathrm{Zn}\left(\mathrm{N}_{2} \mathrm{H}_{5}\right)_{2}\left(\mathrm{SO}_{4}\right)_{2}$ contained $\mathrm{Zn}^{\mathrm{II}}$ ions coordinated by four oxygens of four different $\mathrm{SO}_{4}$ groups and two monodentate $\mathrm{N}_{2} \mathrm{H}_{5}$ groups, in an irregular octahedron.

The $\mathrm{SO}_{4}$ groups are bidentate to two different $\mathrm{Zn}$ ions, yielding infinite chains in one direction. The distances around $\mathrm{Zn}$ are: $\mathrm{Zn}-\mathrm{N} 2.08 \AA \AA, \mathrm{Zn}-\mathrm{O} 2.10$ $2.38 \hat{A}$. Hydrogen bonds with $\mathrm{N}_{2} \mathrm{H}_{5}$ ligands hold the chains together.

The study of Hand and Prout ${ }^{7}$ on similar compounds and the results of the isomorphy study in Iable I, indicate that all compounds of the present investigation have the same basic geometry. As will be shown below, the spectroscopic results are in agreement with this picture. According to the manner of description, distortion of the octahedron around the metal ion can be considered with respect to the nature of the ligands or with respect to the bondlengths.

Regarding the spectrochemical nature of the ligands, the octahedron is tetragonal compressed with a rhombic distortion due to the unequal O-M bond lengths. Regarding the bondlengths, on the other hand, the octahedron can be considered as tetragonal elongated, with a rhombic component due to the different spectrochemical positions of oxygen and nitrogen.

As will be shown below, most of the measurements can be understood on the basis of the compressed octahedron, without rhombic distortion. Only the EPR spectra of the $\mathrm{Cu}$ compounds can be best understood on the basis of an octahedran elongated along the $\mathrm{Cu}-\mathrm{O}$ direction.

This slightly deviating behaviour of the $\mathrm{Cu}$ compusund may be related to the deviating X-ray patterns of the $\mathrm{Cu}^{\text {iI }}$ and $\mathrm{Cd}^{\mathrm{II}}$ compounds that may be due to the nature of the metal ions ( $\mathrm{Cu}$ is rather small and $\mathrm{Cd}$ is rather large in ionic radius). The results are not in agreement with a structure $\mathrm{M}\left(\mathrm{N}_{2} \mathrm{H}_{4}\right)_{2}\left(\mathrm{HSO}_{4}\right)_{2}$, containing bidentate $\mathrm{N}_{2} \mathrm{H}_{4}$, as suggested by Bhargave et al. ${ }^{11}$

Infrared Spectra. The reported absorption bands in Table II and III can all be ascribed to vibrations of either the $\mathrm{N}_{2} \mathrm{H}_{5}{ }^{+}$species, the $\mathrm{SO}_{4}{ }^{2-}$ species, or the $\mathrm{MO}_{4} \mathrm{~N}_{2}$ skelet.

Regarding the vibrations of the $\mathrm{N}_{2} \mathrm{H}_{5}$ groups it is observed that N-H stretches occur as low as 2660 $\mathrm{cm}^{-1}$. This is indicative for strong hydrogen-bond formation with the $\mathrm{SO}_{4}^{2-}$ anions. The two bands at 3290 and $3230 \mathrm{~cm}^{-1}$ on the other hand are due to much weaker hydrogen-bonded $\mathrm{N}-\mathrm{H}$ bands, presumably from the $\mathrm{NH}_{2}$ side of the ligand that is further away from the anions. ${ }^{1}$ There is some doubt about the position of the N-N stretching; possibly the highest one of the doublet near $1000 \mathrm{~cm}^{-1}$ is responsible for this vibration. This is quite high, although hydrazine is also known to have increased $\mathrm{N}-\mathrm{N}$ stretches upon coordination. In addition the Irving-Williams sequence of metal ions holds.

(11) A.P. Bhargave, R. Swaroop, and Y.K. Cupta, J. Chem. Soc., A. 2183 (1970).
Although the S-O stretching vibrations principally should yield information about the bonding of the $\mathrm{SO}_{4}{ }^{2-}$ anions, the manner of coordination cannot be derived from the present spectra, because of the broad bands and the overlap with the $\mathrm{N}-\mathrm{H}$ vibrations. On the other hand, the spectra are not in contradiction with the structure determination of the $\mathrm{Zn}$ compound.

$\mathrm{N}-\mathrm{H}$ deformation vibrations and the $\mathrm{N}-\mathrm{N}$ bending are observed below $700 \mathrm{~cm}^{-1}$. The former occur just around the split $\nu_{4}\left(\mathrm{SO}_{4}\right)$ vibrations near $600 \mathrm{~cm}^{-1}$, yielding a rather complex line pattern of at least four lines. The N-N kending is observed near 480 $\mathrm{cm}^{-1}$ close to the $v_{2}\left(\mathrm{SO}_{4}\right)$ vibration (forbidden in $\mathrm{Td}$ symmetry). It is observed from Table III that the Irving-Williams sequence of metal ions, i.e. $\mathrm{Mn}<$ $\mathrm{Fe}<\mathrm{Co}<\mathrm{Ni}<\mathrm{Cu}>\mathrm{Zn}>\mathrm{Cd}$, also holds for this vibration. This is not unexpected, and has been observed before for many other ligand vibrations. ${ }^{13}$

Below $450 \mathrm{~cm}^{-1}$ we observe the vibrations due to the $\mathrm{MO}_{4} \mathrm{~N}_{2}$ seklet, i.e. the $\mathrm{M}-\mathrm{O}$ and $\mathrm{M}-\mathrm{N}$ stretchings. Due to the complexity of the species, it is impossib to speak of separate $\mathrm{M}-\mathrm{N}$ and $\mathrm{M}-\mathrm{O}$ frequencies, and in fact the band at highest frequency falls close to the region commonly observed for metal-oxygen vibrations $^{12-13}$ and is also in the region of $\mathrm{M}-\mathrm{N}$ found for hydrazine complexes. ${ }^{14}$ Again the Irving-Williams sequence holds.

Ligand-field Spectra. The observed reflectance spectra of the solid compounds are in agreement with a basicly octahedral geometry around the metal ions. However, most bands are very broad and some of them even show splittings. A few splittings become better resolved at low temperatures.

Assuming compressed tetragonal geometry ${ }^{1}$ and using the procedures for the evaluation of parameters given before, ${ }^{8}$ we could calculate values for $\mathrm{Dq}$, Ds, Dt and B for the several compounds. As the octahedron is compressed along the tetragonal axis, the values for Ds and $D t$ are negative.

For the iron compound, only the value for $4 \mathrm{Ds}+$ 5Dt could be determined from the ligand-field spectr? (i.e. equal to the separation between the two ligand. field bands). Combination with the results obtained from the Mössbauer spectra and the magnetic susceptibility measurements, however, yielded separate values for Dt and Ds, as indicated in Table IV.

The parameters for the cobalt compound could be calculated accurately because of the fact that more (split) bands are observed.

The spectra of the nickel compound showed no splittings at all, even not at liquid nitrogen temperatures. After taking a value of $-300 \mathrm{~cm}^{-1}$ for the spin-orbit coupling constant, from the observed line width an upper limit for Ds and Dt could be determined with the aid of a full matrix diagonalization procedure.

As is seen from Table IV the parameters for the

(12) J. Reedijk, P.W.N.M. van Leeuwen, and W.L. Groeneveld, Rec. Traj. Chim., 87, 1073 (1966).

(13) J.R. Ferraro, Low-frequency vibrations of Inorganic and Coordigation Compounds, Plenum, New York, 1971.

(14) L. Sacconi and A. Sabatini, J. Inorg. Nucl. Chem., 25, 1389 (1963). 
$\mathrm{Fe}, \mathrm{Co}$ and $\mathrm{Ni}$ compounds agree very well with each other. For $\mathrm{Cu}\left(\mathrm{N}_{2} \mathrm{H}_{5}\right)_{2}\left(\mathrm{SO}_{4}\right)_{2}$ and for the copper dope in the zinc compound, no parameters could be calculated due to the lacking of sufficient bands.

As can be seen from Table IV, both Dq eand -Ds increase upon cooling to liquid nitrogen temperature. 'The increase in Dq is normal, and has been observed before. The increasing-Ds value corresponds to a greater $T_{2 g}$ splitting, and has also been found in the investigation of the Mössbauer spectra and magnetic susceptibilities (vide infra).

The slight increase in $\mathrm{Dq}^{\mathrm{xy}}$ on going from $\mathrm{Fe}$ to $\mathrm{Ni}$, is just as expected from the decreasing ionic radius, and has been observed previously for pyrazole ligands. ${ }^{8}$

From the $\mathrm{Dt}$ values, the $\mathrm{Dq}^{2}$ value for $\mathrm{N}_{2} \mathrm{H}_{5}{ }^{+}$can be calculated by the relation: $\mathrm{Dq}^{\mathrm{xy}}-7 \mathrm{Dt} / 4=\mathrm{Dq}^{\mathrm{z}}$.

Using $\mathrm{Dq}^{\mathrm{xy}}=0.93 \mathrm{kK}$ and $\mathrm{Dt}=-0.1 \mathrm{kK}$, this yields: $\mathrm{Dq}^{2}=1.1 \mathrm{kK}$, a value quite normal for nitrogen-donor ligands, ${ }^{8}$ but slightly smaller than 1.15 $\mathrm{kK}$ as found for neutral $\mathrm{N}_{2} \mathrm{H}_{4}{ }^{15}$ This smaller value might be due to the positive charge upon the ligand.

In none of the complexes indications were found for the occurrence of rombic splittings in the ligandfield bands. As will be shown below, such splittings are rather small for the iron compound, although EPR spectra of the copper compound clearly show the presence of a rhombic component in the ligandfield (vide infra).

Magnetic and Mössbauer measurements on $\mathrm{Fe}$ $\left(\mathrm{N}_{2} \mathrm{H}_{4}\right)_{2}\left(\mathrm{SO}_{4}\right)_{2}$. For a more detailed study on the ground-state splitting in the iron(II) compound, we have investigated the Mössbauer spectra and the paramagnetic susceptibility between 80 and $300{ }^{\circ} \mathrm{K}$.

Since the ligand-field spectra showed an increase in $-\mathrm{Ds}$ for the present compounds upon cooling, the measurements were carried out in the whole temperature region (Table $\mathrm{V}$ ), to see if the changes are gradually or not.

As is seen from Table $V$, all values change rather gradually upon cooling to liquid nitrogen temperature. The increase in the Mössbauer centre shift (C.S.) is just as expected from the second-order Doppler shift. ${ }^{16}$ The magnitude of the room-temperature C.S. is somewhere between oxygen- and nitrogendonor ligands, in agreement with the proposed structure. (Cf. N-donor ligands with C.S. values from 1.3 - $1.4 \mathrm{~mm} / \mathrm{s}$, and O-donor ligands with values from $1.5-1.6 \mathrm{~mm} / \mathrm{s}){ }^{17-19}$

Principally, the analysis of the quadrupole splittings and the magnetic moments as a function of temperature should yield the parameters $\delta$ (the groundstate splittings, equal to 5Dt-3Ds), $\varepsilon$ (the rhombic splitting), $\lambda$ (the spin-orbit coupling constant), and $k$ (the orbital reduction factor).

However, as the difference between Q.S. $(300 \mathrm{~K})$ and Q.S. (80K) of about $0.7 \mathrm{~mm} / \mathrm{s}$ is higher than the maximum possible increase of about $0.5 \mathrm{~mm} / \mathrm{s}^{20}$

(15) D. Nichols, M. Rowley, and R. Swindells, J. Chem. Soc., A, 950 (1966).

(16) Y. Hazony, J. Chem. Phys., 45, 2664 (1966).

(17) 1. Reedijk, Rec. Trav. Chim., 90, 1285 (1971)

(18) R.H. Herber, Progr. Inorg. Chem., 8, 1 (1967).

A787 (1964).

(20) I.K.L.F. de Vries, Thesis, Nymegen, 1972 such a large increase can be explained only by an increasing ground-state splitting upon cooling, i.e. an increasing $\delta$ and/or $\varepsilon$.

The same appears to be the case for the magnetic moments. For compressed octahedrons we expect a nearly temperature independent behaviour for $\mu$ between 300 and $80 \mathrm{~K}^{21,22}$ The observed decrease in our $\mu$ values can be due to two mechanisms:

a. An increasing value of the ground-state splitting upon cooling, which would be in agreement with the Mössbauer spectra.

b. Antiferromagnetic exchange in the $\mathrm{SO}_{4}$-bridged chains, that has the effect of decreasing $\mu_{\text {eff }}$ upon cooling. A correction is usually made for lattice compounds by setting $\chi$ equal to $\mathrm{C} /(\mathrm{T}-\theta)$. For comparison in Table $V$ the calculated $\mu$-values with a $\theta$-value of -8 have also been listed.

To obtain detailed information about the exact magnitude of $\mathrm{B}$, measurements as low as liquid Helium are necessary. These are in progress for all these compounds. For the moment we will restrict ourselves to a magnetically diluted system, ignoring any antiferromagnetic exchange.

Therefore, we made use of a full matrix consideration of $\mathrm{Fe}^{2+}\left({ }^{5} \mathrm{D}\right)$ under the simultataneous action of octahedral tetragonal and rhombic ligand fields and spin-orbit coupling. In this way we obtained $\mu$ and Q.S. as a function of T, Dq, Ds, Dt, Dr, K and $\lambda$. In the calculation procedures influences of covalency upon the field gradient were ignored, and the lattice contribution was taken to be equal to $0.85 \mathrm{Ds}$ (in $\mathrm{kK}$ ), expressed in $\mathrm{mm} / \mathrm{s}^{3}$

The calculations were carried out on a IBM 360/ 65 computer, using programs-developed by Mr.A. Vermaas. The main program consists of two parts:

a. A part calculating Q.S. splittings; this is a modified version of the program written by de Vries. ${ }^{20}$

b. A part calculating the susceptibilities; this program was set up as published by Figgis et al. ${ }^{21}$ and König et al. ${ }^{22}$, but extended to rhombic splittings and interaction with the higher E-term. Details of the program will be published elsewhere. ${ }^{24}$

In the analyses of the data, we fixed the values of $\mathrm{Dq}$ and of (4D $+5 \mathrm{Dt})$ that were obtained from the ligand-field spectra. Further we used a value of 0.25 barn for the quadrupole moment of ${ }^{57} \mathrm{Fe} .{ }^{19,23}$ The best fit with both measurements was obtained for the following parameters (Table VII):

Table VII. Spectral parameters of $\mathrm{Fe}\left(\mathrm{N}_{2} \mathrm{H}_{5}\right)_{2}\left(\mathrm{SO}_{4}\right)_{2}$.

\begin{tabular}{lccccccc}
\hline Temperature & $\mathrm{Dq}_{x y}{ }^{a}$ & $\mathrm{Ds}^{a}$ & $\mathrm{Dt}^{a}$ & $\mathrm{Dr}^{a, b}-\lambda^{c}$ & $\mathbf{k}$ & $\delta^{a, c}$ \\
\hline $300 \mathrm{~K}$ & 0.91 & -0.4 & -0.1 & 0.3 & 75 & 0.7 & 700 \\
$200 \mathrm{~K}$ & 0.92 & -0.45 & -0.1 & 0.3 & 75 & 0.7 & 850 \\
$100 \mathrm{~K}$ & 0.93 & -0.5 & -0.1 & 0.3 & 75 & 0.7 & 1050 \\
\hline
\end{tabular}

$a$ In $\mathrm{kK}$; ${ }^{b}$ upper limit; $c$ in $\mathrm{cm}^{-1}$

(21) B.N. Figgis, I. Lewis, F.E. Mabbs, and G.A. Webb, J. Chem.

Soc. $A_{\text {(2) }} 442$ (1967). . König and A.S. Chakravarty, Theor. Chim. Acta, 9, 171 (1967). 
The assumption of a $\theta$ value of $-8^{2}$, influences the parameters slightly (i.e. $\lambda$ is increased to about 80 $\mathrm{cm}^{-1}, \mathrm{k}$ is increased to about 0.8 and $\delta$ is decreased by about $10 \%$ ) and even give a better fit. Summarizing, these results indicate:

a. A compressed tetragonal structure, with a ground-state orbital singlet, having a doublet at about 0.7 - $1.0 \mathrm{kK}$ above it.

b. The rhombic splitting of this doublet - if present - is smaller than $0.3 \mathrm{kK}$.

c. The values of $k$ and $\lambda$ indicate some covalency in the Fe-ligand bonds, in agreement with the rather low B-values for the Co and Ni compounds (Table IV).

EPR spectra of some powdered compounds containing $\mathrm{Cu}^{2+}$ or $\mathrm{Mn}^{2+}$. To obtain detailed information about the geometry and the kind of bonding in the present compounds. EPR spectra of the $\mathrm{Mn}^{2+}$ and $\mathrm{Cu}^{2+}$ compounds and impurities of them in the diamagnetic lattices of the $\mathrm{Zn}$ and $\mathrm{Cd}$ were investigated.

From the results in Table VI it is seen that all copper compounds show a three g-value spectrum, characteristic for rhombic geometry. ${ }^{25}$ Wether this three-g-value spectrum is derived from axial elongated (i.e. $\mathrm{g}_{3}=2.0$ and $\mathrm{g}_{2}=\mathrm{g}_{1} \approx 2.4$ ) cannot be directly coneluded from the spectra, although the fact that the lowest g-value is about 2.05 points in to the description of elongated octahedral geometry. Anyway, the rhombic distortion is clearly demonstrated by the occurrence of three separate g-values. The calculated g-values from the spectra were obtained from computer produced simulations, ${ }^{26}$ and for all compounds the results are similar to the observed $X$ and $Q$ band spectra within experimental error.

Copper hyperfine splittings were not observed, except for the dope in the $\mathrm{Zn}$ compound (upon $\mathrm{g}_{3}$ ). In fact the hyperfine coupling constants may be small due to the nature of the metal-ligand bond (usually $\mathrm{Cu}^{2+}$ compounds with oxygen-donor ligands do not show resolved hyperfine splittings), ${ }^{25,27}$ or due to

(23) J. Reedijk and D.W. Engelfriet, Rec. Trav. Chim., 91, 883

(24) A. Vermaas and I. Reedijk, to be published.

(25) B.J. Hathaway and D.E. Billing, Coord. Chem. Rev., 5, 143 (1970)

(26) $T$. Vanngard and $R$. Aasa, in W.Low(Ed)., Paramagnetic Reonance, Vol. 2. p. 163. Academic Press, 1963

(28) R.D. Dowsing and J.F. Gibson, I. Chem. Phys., ,50, 294 (1969). exchange coupling between the $\mathrm{Cu}$ ions. The latter case almost certainly occurs for the pure copper compound.

Exchange coupling must also be responsible for the observed signal of the pure $\mathrm{Mn}^{2+}$ compound. The symmetrical signal, with six inflections assigned to hyperfine interactions, at $\mathrm{g}=\mathbf{2 . 0 1}$ is just as expected for exchange coupled $\mathrm{Mn}$ ions. The dopes in the $\mathrm{Zn}$ and $\mathrm{Cd}$ compounds however, show hyperfine splittings (due to the ${ }^{55} \mathrm{Mn}$ nucleus) as well as fine splittings (due to the zero-field splitting of the ${ }^{6} \mathrm{~A}_{1}$ ground state). From these the parameters $A$ and $D$ and $\lambda$ were calculated using the methods of Dowsing and Gibson. ${ }^{28}$ The slightly larger D value for $\mathrm{Mn}$ doped in the $\mathrm{Cd}$ compound indicates a somewhat larger distortion. The different $\mathrm{D}$ value is in agreement with the observed non-isomorphism of the lattices (Table 1).

\section{Conclusions}

From the results of the present investigation the following conciusions can be drawn:

1. The complexes $\mathrm{M}\left(\mathrm{N}_{2} \mathrm{H}_{5}\right)_{4}\left(\mathrm{SO}_{2}\right)_{2}$ contain bidentate bridging sulfate anions and monopositive monodentate $\mathrm{N}_{2} \mathrm{H}_{5}$ ligands.

2. Most spectral and magnetic measurements are in agreement with a coordination polyhedron build up by two nitrogens (trans) and described by a tetragonal compression with an additional rhombic splitting. The EPR spectra indicate rhombic symmetry derived from elongated octahedral geometry, on the other hand.

3. The presence of this rhombic distortion could not be proved from infrared, ligand-field and Mössbauer spectra and from magnetic susceptibilities.

4. The ligand $\mathrm{N}_{2} \mathrm{H}_{5}{ }^{+}$behaves as a normal nitrogen donor ligand, with a crystal-field splitting somewhat smaller than neutral hydrazine, which might be explained by the positive charge upon the ligand.

Acknowledgement. The authors are indebted to Dr. W.L. Groeneveld and to Prof. Dr. Ir. J.J. Steggerda (University of Nijmegen) who kindly read the manuscript. 